\title{
Children with Relapsed or Refractory Nephroblastoma: Favorable Long-term Survival after High-dose Chemotherapy and Autologous Stem Cell Transplantation
}

\author{
Vorteilhaftes Langzeitüberleben von Kindern mit rezidivierten Nephroblastomen \\ nach Hochdosis-Chemotherapie und autologem Stammzellrescue
}

Authors

Affiliations
T. Illhardt ${ }^{1 *}$, M. Ebinger ${ }^{2 *}$, C. P. Schwarze ${ }^{1}$, T. Feuchtinger ${ }^{1}$, R. Furtwängler ${ }^{2}$, P. G. Schlegel ${ }^{3}$, T. Klingebiel ${ }^{4}$, J. Greil ${ }^{5}$, J. F. Beck ${ }^{6}$, R. Handgretinger ${ }^{1}$, P. Lang

Affiliation addresses are listed at the end of the article

\section{Key words \\ - nephrobastoma \\ - stem-cell transplantation \\ - high-dose chemotherapy \\ - Wilm's disease \\ Schlüsselwörter \\ - Wilmstumor \\ - Nephoblastom \\ - autologes Stammzellrescue \\ - Hochdosischemotherapie}

\section{Abstract}

$\nabla$

Background: High-dose chemotherapy (HDC) with autologous stem-cell rescue (ASCR) is a treatment option for pediatric patients with relapsed nephroblastoma. We present long term results of 9 patients treated between 1993 and 2013 at our center.

Procedure: Reinduction therapy was carried out according to GPOH and SIOP recommendations. The conditioning regimen consisted of carboplatin $\left(1200 \mathrm{mg} / \mathrm{m}^{2}\right)$, etoposide $\left(800 \mathrm{mg} / \mathrm{m}^{2}\right.$ or $40 \mathrm{mg} / \mathrm{kg})$ and melphalan $\left(180 \mathrm{mg} / \mathrm{m}^{2}\right)$. Purging of the grafts with immunomagnetic CD34 positive selection was performed in 5 patients.

Results: 8 of 9 Patients ( $90 \%$ ) are alive without evidence of disease after a median follow-up of 8.5 years. Leukocyte engraftment occurred after a median of 10 days (range 8-12). Median numbers of $667 / \mu \mathrm{l} \mathrm{CD} 3+, 329 / \mu \mathrm{l} \mathrm{CD} 4+, 369 / \mu \mathrm{l} \mathrm{CD} 8+\mathrm{T}$ cells and $949 / \mu$ B cells were reached after 180 days. No negative impact of CD34 selection was observed. No transplantation-related death occurred. Acute toxicity comprised mucositis $\mathrm{III}^{\circ}-\mathrm{IV}^{\circ}$ in all and veno-occlusive disease in one patient. Long term effects probably related to treatment occurred in 3/7 evaluable patients and comprised hearing impairment, reduced renal phosphate reabsorption, mild creatinine elevation and hypothyroidism ( $\mathrm{n}=1$, each).

Conclusion: Thus, in our experience HDC with ASCR is an effective treatment of recurrent or refractory nephroblastoma with acceptable side effects. However, a randomized trial proving its efficiency with a high level of evidence is needed.

${ }^{*}$ Toni Illhardt and Martin Ebinger contributed to this work equally and share first authorship.

\section{Zusammenfassung \\ V}

Hintergrund: Hochdosischemotherapie mit autologem Stammzellrescue ist eine Therapieoption für paediatrische Patienten mit rezidivierten Nephroblastomen. Wir präsentieren Langzeitergebnisse von 9 Patienten, die in den Jahren 1993-2013 in unserem Zentrum auf diese Weise therapiert wurden.

Methods: Reinduktionstherapie wurde nach Empfehlung der SIOPH-GPOH durchgeführt. Das Konditionierungsregime bestand aus Carboplatin $\left(1200 \mathrm{mg} / \mathrm{m}^{2}\right)$, Etoposid $\left(800 \mathrm{mg} / \mathrm{m}^{2}\right.$ oder $40 \mathrm{mg} / \mathrm{kg}$ ) und Melphalan $\left(180 \mathrm{mg} / \mathrm{m}^{2}\right)$. Immunomagnetische $\mathrm{CD}-34$ positive Selektion wurde bei 5 Patienten durchgeführt.

Results: 8 von 9 Patienten sind nach einem medianen Follow-Up von 8,5 Jahren ohne Nachweis der Erkrankung am Leben. Der LeukozytenTake wurde im Median nach 10 Tagen erreicht (Range 8-12). Nach 180 Tagen wurden hinsichtlich der Immunrekonstitution im Median

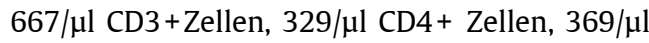

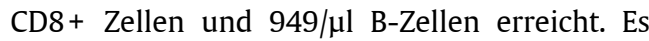
wurde kein negativer Einfluss auf die Immunrekonstitution durch CD34-Selektion beobachtet. Kein Patient starb an den Nebenwirkungen der Transplantation. Die akuten Nebenwirkungen beinhalten Mukositis ${ }^{\circ} \mathrm{III}-{ }^{\circ} \mathrm{IV}$ bei allen Patienten und veno-occlussive disease (VOD) bei einem Patienten. Langzeitfolgen, die eventuell mit der Therapie in Zusammenhang stehen traten in 3/7 evaluierbaren Patienten auf und beinhalten Hörstörungen, leichte Kreatininerhöhung, Störung der Phosphatrückresorption und Hypothyreodismus (jeweils $1 \times$ ).

Schlussfolgerung: Nach unserer Erfahrung ist Hochdosischemotherapie mit autologem Stammzellrescue eine effektive Therapieoption für rezidivierte und refraktäre Nephroblastome mit tolerablen Nebenwirkungen. Jedoch ist eine große randomisierte Studie notwendig um die Effizienz mit hoher Evidenz beweisen zu können. 


\section{Introduction \\ 7}

In the SIOP93-01/GPOH (International Society of Paediatric Oncology/Society for Paediatric Oncology and Haematology) trial $9 \%$ of all patients with a localized nephroblastoma suffered from recurrence [18]. This rate is even higher in patients with one or more risk factors including unfavorable/high risk histology, older patients, bilateral disease and high tumor stage. Metastatic disease at diagnosis (Stage IV) for example reduces the EFS to $72 \%$ in GPOH patients [20]. Fortunately, the outcome of patients with recurrent disease has greatly improved over the last 30 years. While the overall survival before the mid-1980s hardly reached $20-30 \%[7,8,17,23]$, current treatment regimens are able to accomplish survival rates between $45-60 \%$ for relapsed patients $[1,4,13,14,22]$. Especially the introduction of carboplatin, etoposide and ifosfamide in the late 80s and early 90s resulted in a major improvement in survival rates [16]. At the moment 3 year overall survival for standard risk relapse reaches 75-85\% [5]. In contrast, high and very high risk relapse patients have a significantly lower survival (50-60\% and 15-25\%) $[5,19]$ and might potentially profit from increased treatment intensity. The significance of high-dose chemotherapy (HDC) in connection with autologous stem-cell rescue (ASCR) remains undetermined. As stated by previous studies there is evidence for this method to be very effective in treating relapsed nephroblastoma $[3,5,6,11,12,15,19]$. Promising 3- to 5-year survival rates between $30 \%$ and $60 \%$ have been reported. Recently a retrospective analysis from the GPOH compared 26 matched cases receiving and not receiving HDC and ASCR resulting in $64 \%$ vs. $45 \% 3$ year-overall survival $(p=0.059)$ [5]. However, the number of cases in these studies is small and due to the small number of patients with high risk relapsed nephroblastoma in general, randomized studies are hard to perform. Thus, more research on this topic seems to be necessary. The purpose of this paper is to report the experience with HDC and ASCR in terms of survival, side effects and long term toxicity.

\section{Patients and methods}

$\nabla$

Between 1993 and 2013, 9 patients with relapsed or primary refractory nephroblastoma were enrolled in this retrospective monocenter analysis. All of them were treated with HDC and ASCR. Informed consent was obtained from the legal guardians and patients. Table 1 gives an overview about patient characteristics and medical history before HDC. The median age at initial diagnosis was 53 months (Range 11-111 months). According to the SIOP2001/GPOH trial protocol tumor histology was stratified into 3 risk groups (low-risk, intermediate-risk and highrisk). Histological stratification was performed by central pathology review and revealed intermediate-risk tumors in 6 patients and high-risk tumors in 2 patients. The histology of patient \# 7 was not determined by reference pathology. 4 patients were diagnosed with stage IV disease, 3 of them with pulmonary metastases and one with multiple metastases in lung, liver and pancreas.

\section{Initial therapy}

All patients were treated with preoperative chemotherapy. Preand postoperative chemotherapy included actinomycin D and vincristine in 3 patients, 5 patients additionally received doxorubicin. Due to tumor progression under chemotherapy, postop- erative treatment of patient \#1 was changed to the high risk arm (cyclophosphamide, doxorubicin, etoposide and carboplatin) after surgery. In all other patients postoperative chemotherapy consisted of additional courses of the initial treatment. $5 \mathrm{~Pa}$ tients received local radiotherapy with $15 \mathrm{~Gy}$ cumulative dose after surgery ( $\odot$ Table 1 ).

\section{Relapse}

- Table 2 gives an overview about the time to relapse and the site of relapse. 6 patients relapsed after a median of 8 months (Range 6-14 months). Progression under primary therapy occurred in 2 patients and one patient showed only partial remission under initial treatment. One patient (\# 4) experienced 2 relapses before HDC. The first local recurrence was treated with an additional surgical intervention in combination with standard chemotherapy (carboplatin + etoposide) and local irradiation. This second relapse with metastases in liver and lung (after 5 months) was treated with salvage therapy (ifosfamide, carboplatin and etoposide), HDC and ASCR. Most relapses occurred in the lung (6 patients), followed by liver ( 2 patients) and CNS (2 Patients).

Salvage chemotherapy consisted of ifosfamide, carboplatin and etoposide (ICE) in 6 patients according to the recommendation of the SIOP-GPOH, one patient received doxorubicin in addition to ICE and 3 patients were treated with carboplatin and etoposide only ( $\bullet$ Table 2 ).

\section{HDC and ASCR}

HDC was considered as treatment for patients with high risk relapse according to the recommendation of the SIOP-GPOH 2001 trial or for primary refractory/progressive patients. The criteria for high risk relapsed nephroblastoma are shown in 0 Table 3. All patients met at least one criterion. HDC was performed after salvage therapy. Remission status before HDC is shown in - Table 2. 6 patients had complete remission, 1 patient showed partial remission and 2 patients had progressive disease prior to HDC. Peripheral stem cells were harvested after mobilization with G-CSF. CD34-enrichment with Magnetic-activated Cell Sorting (MACS) was performed between 1994 and 2005 in 5 patients as seen in $\odot$ Table 2. After 2005, unmanipulated peripheral stem cells were used for transplantation. The conditioning therapy consisted of a 3-drug regimen containing carboplatin $\left(400 \mathrm{mg} / \mathrm{m}^{2} / \mathrm{d}\right.$ over 3 days), etoposide $\left(800 \mathrm{mg} / \mathrm{m}^{2}\right.$ or $40 \mathrm{mg} / \mathrm{kg}$ BW on one day) and melphalan ( $45 \mathrm{mg} / \mathrm{m}^{2} / \mathrm{d}$ over 4 days) (CEM). The target dose for carboplatin was adjusted according to GFR monitoring: 1. For patients with prior nephrotoxic therapy: calculated target dose in percent $(\% \mathrm{CTD})=(0.65 \times \mathrm{GFR})+18$. 2 . For patients without prior nephrotoxic therapy: $\% \mathrm{CTD}=(0.82 \times$ GFR)+18. Adjuvant radiotherapy was performed in 3 patients with a cumulative dose of $15 \mathrm{~Gy}$ to the relapse tumor bed.

\section{Statistics}

Event-free survival (EFS) and overall survival were estimated by Kaplan-Meyer-Method. Data analysis was performed using SPSS $^{\circledR}$ (Version 20).

\section{Follow-up}

Regular follow-up examination was performed 1, 2, 3, 6, 12, 18, $24,36,48,60,84$ and 120 months after transplantation. Routinely accomplished investigations included blood samples, ultrasound scans of the abdomen and the thyroid gland, bone 


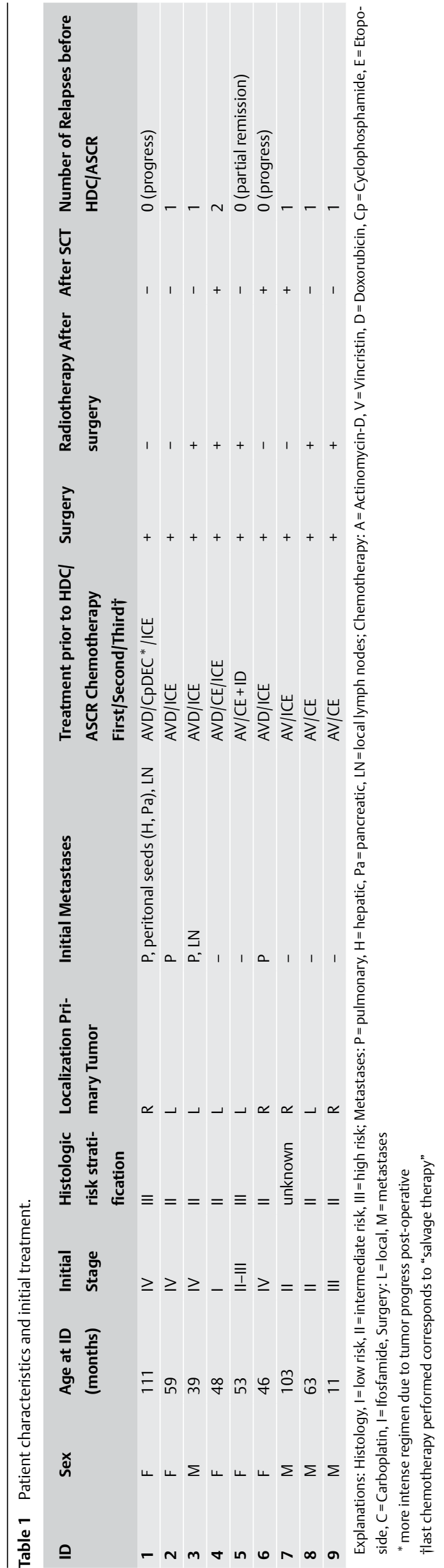

marrow biopsies, spirometries, ECG, echocardiography, ophthalmologic and otorhinolaryngologic examination.

\section{Results \\ $\nabla$ \\ Acute toxicity}

Acute toxicity after stem-cell transplantation was classified according to adapted National Cancer Institute Common Terminology Criteria 3.0. No transplant related mortality occurred. Acute side effects of the conditioning regimen consisted of mucositis $\mathrm{III}^{\circ}-\mathrm{IV}^{\circ}$ requiring continuous morphine therapy as well as parenteral nutrition in all patients. 5 patients developed diarrhea. Nausea was observed in 5 patients. Fever during aplasia occurred in 8 patients without identification of infectious agents. Transient renal involvement with elevated creatinine ( $>3.0 \times$ upper limit of normal [ULN]) and also transient elevated levels of bilirubin $(>3.0 \times \mathrm{ULN})$, AST and ALT $(>5.0 \times \mathrm{ULN})$ occurred in 7 and in 4 patients, respectively.

One patient (ID1) developed hepatic veno-occlusive disease (VOD) with portal flow reversal under conditioning therapy. Multiple hepatic metastases in this patient might have increased the risk. Under the treatment with defibrotide the VOD resolved. Unfortunately this patient died a few weeks later due to tumor progression.

No cardiac, pulmonary or neurological side effects were observed.

\section{Engraftment}

A median number of $10.2 \times 10^{6} \mathrm{CD} 34+$ stem cells per $\mathrm{kg}$ BW were infused (Range 1-16.84) as seen in $\odot$ Table 2. All patients received G-CSF after transplantation. Absolute leukocyte count $>1000 / \mu \mathrm{l}$ (ALC) and absolute neutrophile count $>500 / \mu \mathrm{l}$ (ANC) were reached after a median time of 10 days (Range: ALC $8-12$, ANC 8-15). Flow cytometry analyses were performed on day $14,21,30,60,90,180$ and 365 after ASCR and later on after variable intervals. Reconstitution of lymphocyte subsets over the first year after ASCR is shown in $\odot$ Fig. 1. Median T-Lympho-

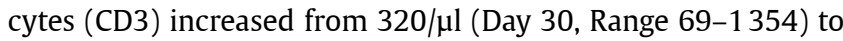

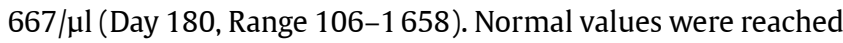
after 1 year $(>1000 / \mu \mathrm{l})$. Median Cytotoxic T cells (CD8) increased

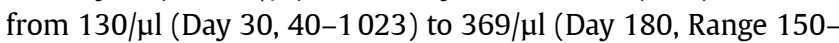
698). Median T helper cells increased from $240 / \mu l$ (Day 30, Range

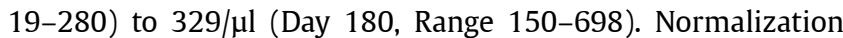
was reached after one year $(>500 / \mu \mathrm{l})$. Median B-lymphocytes

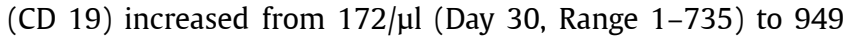
(Day 180, Range 329-1375). These elevated levels normalized after 3 years (not shown).

\section{Long term toxicity}

Long term toxicity effects after a median follow-up of 8.5 years were observed in 3 of 7 evaluable patients. Patient \#1 was excluded due to early death and very short follow-up period. Patient \#7 has been lost to follow-up. One patient suffered from hearing impairment for high frequencies, mitral regurgitation, lowered renal phosphate re-absorption and elevated levels of estrogens. One patient showed mild elevation of creatinine $(0.9 \mathrm{mg} / \mathrm{dl}, \mathrm{ULN} 0.8 \mathrm{mg} / \mathrm{dl})$ and one patient was diagnosed with hypothyroidism during this follow-up period. The role of chemotherapy in the development of these late side effects remains undetermined. Incidental findings should be considered. In all other patients there were no signs of long term toxicity. 
Table 2 Relapse, HDC parameters and outcome.

\begin{tabular}{|c|c|c|c|c|c|c|c|c|}
\hline ID & $\begin{array}{l}\text { Time to } \\
\text { Relapse }\end{array}$ & $\begin{array}{l}\text { Site of } \\
\text { Relapse }\end{array}$ & $\begin{array}{l}\text { Status before } \\
\text { HDC/ASCR }\end{array}$ & $\begin{array}{l}\text { Infused CD } 34+\text { cells } \\
\times 10^{6} \text { per kg BW }\end{array}$ & $\begin{array}{l}\text { CD34- } \\
\text { Enrichement }\end{array}$ & $\begin{array}{l}\text { RT after } \\
\text { HDC/ASCR }\end{array}$ & Outcome & $\begin{array}{l}\text { Follow-up Interval } \\
\text { (months) }\end{array}$ \\
\hline 1 & - & - & progression & 7.89 & - & - & DOD & 0.7 \\
\hline 2 & 9 & $P$ & CR 2 & 16.84 & + & - & NED & 92 \\
\hline 3 & 14 & $\mathrm{P}$ & CR 2 & 7.06 & - & - & NED & 7.7 \\
\hline 4 & 8 & 1. local & CR 3 & 10.2 & - & + & NED & 124 \\
\hline 5 & $0^{*}$ & $\mathrm{H}$ & CR1 & 18 & + & - & NED & 127 \\
\hline 6 & - & CNS, P & progression & 14.41 & + & + & NED & 102 \\
\hline 7 & 14 & $\mathrm{P}$ & PR & 1.91 & - & + & NED & 101 \\
\hline 8 & 6 & Sp & CR 2 & 1 & + & - & NED & 189 \\
\hline 9 & 8 & $P$ & CR 2 & 15.4 & + & - & NED & 109 \\
\hline
\end{tabular}

Explanations: $C R=$ Complete Remission; $P R=$ Partial remission; $H D C=$ high-dose chemotherapy; $P=$ pulmonary; $H=$ hepatic; $\mathrm{SP}=$ spinal; $R T=$ Radiotherapy; $D O D=$ died of disease; NED $=$ no evidence of disease

${ }^{*}$ hepatic metastases occurred directly after initial treatment

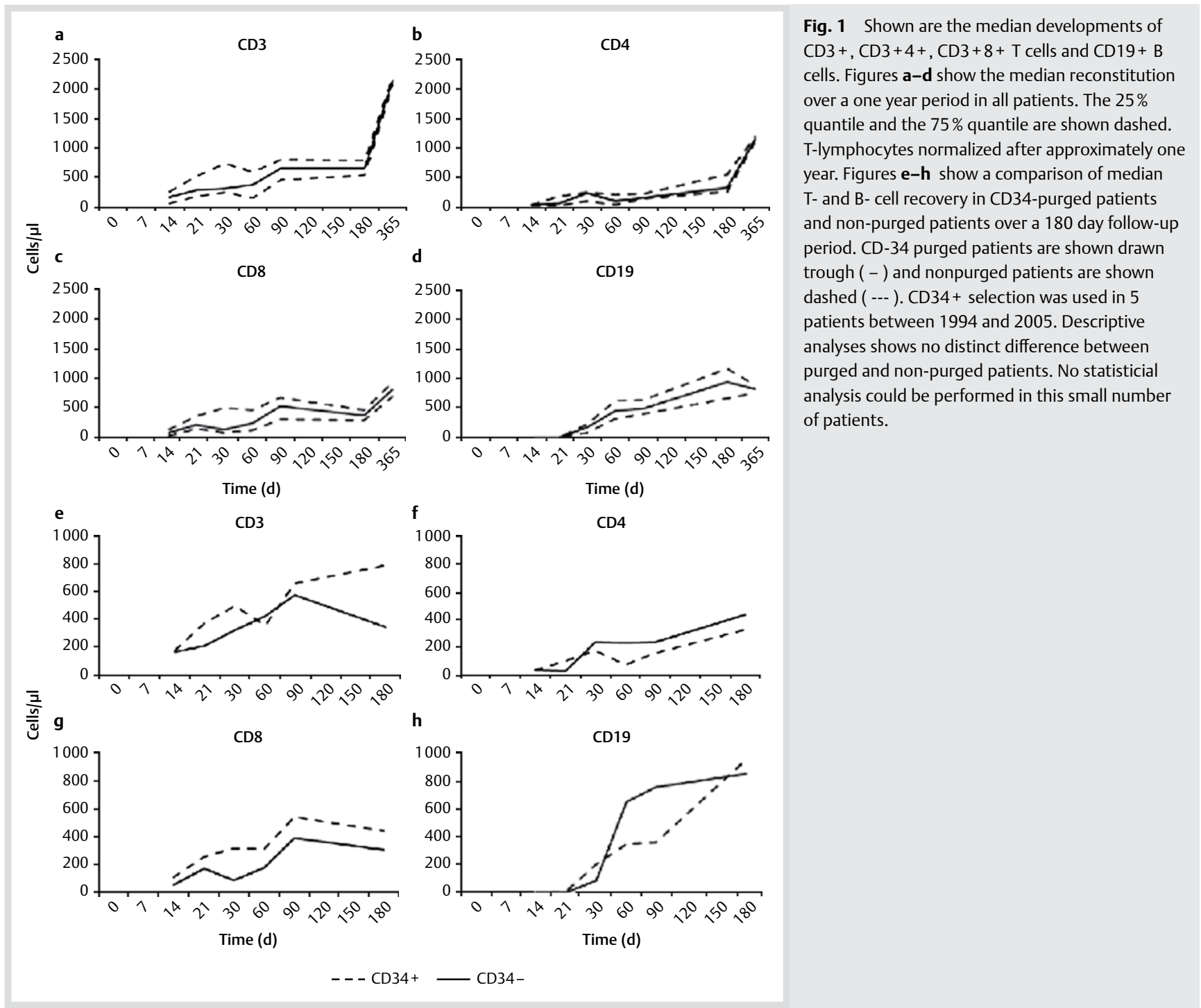

\section{Survival}

Event-free survival was defined as relapse-free or progressionfree time after transplantation. 8 of 9 patients (90\%) are alive with no evidence of disease after a median follow-up of 8.4 years (Range 0.06-15.5). Only one patient with progressive disease prior to transplant died during salvage therapy 3 weeks after HDC due to tumor progress. On the contrary the outcome of an- other patient (\# 6) with progressive disease before transplantation was favorable. This patient received local irradiation in addition to HDC and is alive without evidence of disease after 8.4 years of follow-up. The patient with partial response (ID 7) was also irradiated for local tumor control. 
Table 3 Definition of high-risk relapsed nephroblastoma according to the SIOP-GPOH 2001 protocol.

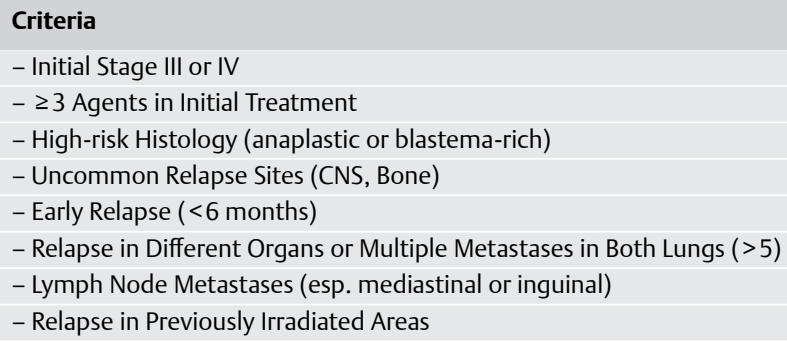

\section{Discussion}

$\nabla$

The significance of high-dose chemotherapy (HDC) in combination with autologous stem-cell rescue (ASCR) still remains unclear in relapsed nephroblastoma since randomized studies with a high number of cases are lacking. However, several non-randomized studies have shown favorable overall survival and eventfree survival rates between 34-64\% (13-19) and HDC with ASCR therefore seems to be a very effective way to treat relapsed nephroblastoma. We could confirm these results in our retrospective, monocenter analysis with a long term EFS of $90 \%$ after a median follow-up of 8.4 years. Since 7 patients are in complete remission after a follow-up of more than 7 years, recurrence in these patients is most unlikely. However, our results are limited by several factors of influence: the number of cases was low, the initial therapy was not standardized and a heterogeneous group of patients had to be recruited for analysis.

With these results, we cannot definitely answer the question whether HDC therapy is superior to a non-HDC approach or not. A recent meta-analysis by Ha et al. [9] pointed out that further data on this topic is needed, especially for the rarer subgroups, i.e., high-risk histology. However, this meta-analysis showed that HDC might be more effective in terms of both EFS and OS, compared to non-HDC treatment. The authors pointed out that especially patients in the high risk (every patient with initial RT, $\geq 3$ drugs during initial treatment, initial use of ifosfamide or cyclophosphamide) or very high risk subgroups (stage IV disease with unfavorable histology, initial therapy with 4 or more chemotherapeutic agents, $>1$ relapse or refractory relapse) seem to benefit from HDC treatment with improved EFS. The calculated hazard ratios were 0.97 (95\% CI 0.43-2.71, p=0.94), $0.90(95 \% \mathrm{CI}$ $0.62-1.31, \mathrm{p}=0.6)$ and $0.50(95 \% \mathrm{CI} 0.31-0.82 . \mathrm{p}=0.006)$ for the standard, high and very high risk subgroups respectively as compared to non-HDC treatment. This suggests a significant benefit for the very high risk subgroup and a potential benefit for the high risk group, whereas the benefit for the low risk group seems negligible. The estimated 3-year EFS for standard, high and very high risk were $59.5 \%, 49 \%$ and $27.2 \%$ respectively over all relapsed patients (treated with or without HDC). In conclusion the potential benefit of HDC therapy in comparison to Non-HDC treatment is directly correlated to the individual risk profile of the patient. All but one patient (\#7) of our analysis met their criteria for high or very high risk relapse. These criteria do not coincide with the risk stratification by the SIOP/GPOH normally used for high risk nephroblastoma ( 0 Table 3 ).

On the other hand, possible side effects of HDC must be taken into consideration. Myeloablative regimens tend to increase the possibility of critical side effects like infections or veno-occlusive disease. Therefore treatment-related mortality might be higher than in conventional regimens [21]. However, conflicting results are reported regarding this issue, since a recent metaanalyses performed by Yalcin et al. could not show any significant increase in treatment related mortality, severe infections and sepsis between myeloablative approaches and conventional approaches in the treatment of high-risk neuroblastoma. Nevertheless they found a higher incidence of renal effects, interstitial pneumonitis and VOD in the myeloablative group [24].

In our analysis no treatment related death occurred. One patient developed VOD which might be at least partially triggered by hepatic metastases. All other patients had only mild and reversible acute toxicities. These results are in line with observations from other investigators and the CEM-Regimen in particular has been considered to be well tolerated with low therapy related mortality [2].

Long term toxicity after HDC/ASCR is not well evaluated and studies about this topic are very rare. Moreover, the contribution of HDC in the development of long term side effects is difficult to determine considering the fact that all patients received different pre-HDC therapies. Possible late effects cannot be differentiated from other late effects caused by the chemotherapeutical agents used for the HDC. This includes chronic renal, pulmonary or cardiac dysfunction, impairment of the visual or auditory systems, changes in the hormonal systems and secondary malignancies. In our experience, long term toxicity was acceptable since only one patient of 6 evaluable patients suffered from serious long term side effects (hearing impairment, mitral regurgitation, renal dysfunction and elevated estrogens).

CD34-enrichement was used in 5 patients. The purpose was to deplete the graft of any remaining nephroblastoma cells in order to reduce relapse probability. As shown by Handgretinger et al. [10] CD34 purging is an effective way to reduce graft contamination without hampering the immune recovery. Although this study was performed on patients with high-risk neuroblastoma, we assume that the conclusions can be transferred to nephroblastoma patients. As depicted in $\odot$ Fig. 1, the reconstitution of the observed subtypes does not show any obvious difference between CD34-purged patients and non-purged patients. Due to the low patient numbers, we were not able to demonstrate positive effects on the relapse probability due to CD34 selection in this analysis and probably no large randomized study will have the statistical power to clarify this issue. However, we have not observed any detrimental side-effects like severe infections or delayed immune reconstitution in our patients with CD34 selected grafts. Although the clinical benefit remains unclear, CD34-enrichment may be feasible to reduce tumor cells in the transplant without increasing the side effects.

\section{Conclusion \\ $\nabla$}

In our experience HDC with ASCR is an effective way to treat recurrent or refractory nephroblastoma and should be considered as the primary relapse therapy for patients under very high risk. An excellent long term survival without evidence of recurrent disease and with few side effects could be observed.

However, the number of patients analyzed here is small and further investigations on this topic are needed.

We suggest a large, standardized, preferably international, randomized trial to determine the role of HDC in terms of survival and toxicity in relapsed and refractory nephroblastoma. 


\section{Contributor's Statement}

$\nabla$

All authors have contributed to this work in significant ways and agreed upon the content.

Conflict of interest: The authors have no conflict of interest to disclose.

\section{Affiliations}

Department of Pediatric Oncology, University Children's Hospital,

Tuebingen, Germany

Department of Pediatric Oncology, University of Saarland, Homburg, Germany

${ }^{3}$ Departments of Pediatric Hematology and Oncology, and Stem Cell Transplantation Program, University Children's Hospital, University of Wuerzburg, Wuerzburg, Germany

${ }^{4}$ Department of Pediatric Oncology, University Hospital Frankfurt, University of Frankfurt, Frankfurt, Germany

Pediatric Oncology and Hematology, University Hospital Heidelberg, Heidelberg, Germany

Department of Pediatric Hematology and Oncology, University Hospital

Jena, Jena Germany

\section{References}

1 Abu-Ghosh AM, Krailo MD, Goldman SC et al. Ifosfamide, carboplatin and etoposide in children with poor-risk relapsed Wilms' tumor: a Children's Cancer Group report. Annals of oncology: official journal of the European Society for Medical Oncology/ESMO 2002; 13: 460-469

2 Benedetti Panici P, Pierelli L, Scambia G et al. High-dose carboplatin, etoposide and melphalan (CEM) with peripheral blood progenitor cell support as late intensification for high-risk cancer: non-haematological, haematological toxicities and role of growth factor administration. British journal of cancer 1997; 75: 1205-1212

3 Campbell AD, Cohn SL, Reynolds $M$ et al. Treatment of relapsed Wilms' tumor with high-dose therapy and autologous hematopoietic stemcell rescue: the experience at Children's Memorial Hospital. Journal of clinical oncology: official journal of the American Society of Clinical Oncology 2004; 22: 2885-2890

4 Dome JS, Liu T, Krasin M et al. Improved survival for patients with recurrent Wilms tumor: the experience at St. Jude Children's Research Hospital. Journal of pediatric hematology/oncology 2002; 24: 192-198

5 Furtwängler R, Nourkami N, Alkassar $M$ et al. Update on relapses in unilateral nephroblastoma registered in 3 consecutive SIOP/GPOH studies - A report from the GPOH-nephroblastoma study group. Klinische Padiatrie 2011; 223: 113-119

6 Garaventa A, Hartmann O, Bernard JL et al. Autologous bone marrow transplantation for pediatric Wilms' tumor: the experience of the European Bone Marrow Transplantation Solid Tumor Registry. Medical and pediatric oncology 1994; 22: 11-14

7 Groot-Loonen JJ, Pinkerton CR, Morris-Jones PH et al. How curable is relapsed Wilms' tumour? The United Kingdom Children's Cancer Study Group. Archives of disease in childhood 1990; 65: 968-970

8 Grundy P, Breslow N, Green DM et al. Prognostic factors for children with recurrent Wilms' tumor: results from the Second and Third National Wilms' Tumor Study. Journal of clinical oncology: official journal of the American Society of Clinical Oncology 1989; 7: 638-647

$9 \mathrm{Ha}$ TC, Spreafico F, Graf $N$ et al. An international strategy to determine the role of high dose therapy in recurrent Wilms' tumour. European journal of cancer 2013; 49: 194-210
10 Handgretinger $R$, Lang $P$, Ihm $K$ et al. Isolation and transplantation of highly purified autologous peripheral CD34(+) progenitor cells: purging efficacy, hematopoietic reconstitution and long-term outcome in children with high-risk neuroblastoma. Bone marrow transplantation 2002; 29: 731-736

11 Hempel L, Kremens B, Weirich A et al. High dose consolidation with autologous stem cell rescue (ASCR) for nephroblastoma initially treated according to the SIOP 9/GPOH trial and study. Klinische Padiatrie 1996; 208: 186-189

12 Kremens B, Gruhn B, Klingebiel T et al. High-dose chemotherapy with autologous stem cell rescue in children with nephroblastoma. Bone marrow transplantation 2002; 30: 893-898

13 Malogolowkin M, Cotton CA, Green DM et al. Treatment of Wilms tumor relapsing after initial treatment with vincristine, actinomycin $D$, and doxorubicin. A report from the National Wilms Tumor Study Group. Pediatric blood \& cancer 2008; 50: 236-241

14 Park ES, Kang HJ, Shin HY et al. Improved survival in patients with recurrent Wilms tumor: the experience of the Seoul National University Children's Hospital. Journal of Korean medical science 2006; 21: 436-440

15 Pein F, Michon J, Valteau-Couanet D et al. High-dose melphalan, etoposide, and carboplatin followed by autologous stem-cell rescue in pediatric high-risk recurrent Wilms' tumor: a French Society of Pediatric Oncology study. Journal of clinical oncology: official journal of the American Society of Clinical Oncology 1998; 16: 3295-3301

16 Pein F, Tournade MF, Zucker JM et al. Etoposide and carboplatin: a highly effective combination in relapsed or refractory Wilms' tumor - a phase II study by the French Society of Pediatric Oncology. Journal of clinical oncology: official journal of the American Society of Clinical Oncology 1994; 12: 931-936

17 Pinkerton CR, Groot-Loonen JJ, Morris-Jones PH et al. Response rates in relapsed Wilms' tumor. A need for new effective agents. Cancer 1991; 67: 567-571

18 Reinhard H, Aliani S, Ruebe C et al. Wilms' tumor in adults: Results of the Society of Pediatric Oncology (SIOP) 93-01/Society for Pediatric Oncology and Hematology (GPOH) Study. Journal of Clinical Oncology 2004; 22: 4500-4506

19 Spreafico F, Bisogno G, Collini P et al. Treatment of high-risk relapsed Wilms tumor with dose-intensive chemotherapy, marrow-ablative chemotherapy, and autologous hematopoietic stem cell support: experience by the Italian Association of Pediatric Hematology and Oncology. Pediatric blood \& cancer 2008; 51: 23-28

20 Warmann SW, Furtwangler R, Blumenstock $G$ et al. Tumor biology influences the prognosis of nephroblastoma patients with primary pulmonary metastases: results from SIOP 93-01/GPOH and SIOP 2001/ GPOH. Annals of surgery 2011; 254: 155-162

21 Weaver CH, Schwartzberg LS, Hainsworth J et al. Treatment-related mortality in 1000 consecutive patients receiving high-dose chemotherapy and peripheral blood progenitor cell transplantation in community cancer centers. Bone marrow transplantation 1997; 19: 671-678

22 Weirich A, Ludwig $R$, Graf $N$ et al. Survival in nephroblastoma treated according to the trial and study SIOP-9/GPOH with respect to relapse and morbidity. Annals of oncology: official journal of the European Society for Medical Oncology/ESMO 2004; 15: 808-820

23 Wilimas JA, Champion J, Douglass EC et al. Relapsed Wilms' tumor. Factors affecting survival and cure. American journal of clinical oncology 1985; 8: 324-328

24 Yalcin B, Kremer LC, Caron HN et al. High-dose chemotherapy and autologous haematopoietic stem cell rescue for children with highrisk neuroblastoma. The Cochrane database of systematic reviews 2013; 8: CD006301 